\title{
兴安落叶松人工林腐殖质阴燃燃烧温度变化特征
}

\author{
尹赛男 ${ }^{1}$, 杜 帅 $^{2}$, 单延龙 ${ }^{1,}$, 高 博 ${ }^{1}$, 王明霞 ${ }^{1}$, 韩喜越 ${ }^{1}$, 张 吴 $^{1}$ \\ 1 北华大学林学院,北华大学森林草原防灭火科技创新中心,吉林 132013 \\ 2 长春市安全生产应急指挥及安全监管信息中心,长春 130022
}

摘要:森林地下火是发生在腐殖质层的一种缓慢、无焰、低温、持久的阴燃燃烧,整个燃烧过程都是靠自身所释放的热量所维持。 所以地下火发生时产生的温度是研究其火行为特征的重要指标, 更是森林地下火监测和扑救过程中的重要依据。以大兴安岭 地区 5 种地类下人工种植的兴安落叶松林为研究对象, 以室内控制点烧实验为基础, 研究不同地类和腐殖质粒径阴燃燃烧的温 度变化特征。结果表明:不同粒径的腐殖质阴燃燃烧最高温度之间不存在显著差异 $(P>0.05)$, 而不同地类和二者的交互作用 对阴燃燃烧最高温度的影响则存在显著差异 $(P<0.05) ; 4$ 种腐殖质粒径下不同地类之间的阴燃燃烧最高温度都存在显著差异 $(P<0.05)$ 。任意一种腐殖质粒径下塔头甸子的阴燃燃烧温度都是最高的,最高可达 $897.53^{\circ} \mathrm{C}$, 其次是水湿地, 有坡山地、无坡 山地、农用地的腐殖质阴燃燃烧温度较低。不同地类的腐殖质燃烧地表温度较高, 最高温度可达 $618.83^{\circ} \mathrm{C}$; 随着燃烧时间的增 加, 腐殖质燃烧的地表温度随之降低, 二者之间关系可以用 $y=a \times x^{b}$ 方程拟合, 并且拟合程度高 $\left(R^{2}>0.9, P<0.01\right)$ 。相关研究 成果可以为该地区森林地下火监测扑救提供科学有效的理论依据。

关键词: 兴安落叶松人工林; 腐殖质; 阴燃燃烧; 温度变化

\section{Characteristics of humus smoldering combustion temperature changes in Larix gmelinii plantation}

\author{
YIN Sainan ${ }^{1}$, DU Shuai ${ }^{2}$, SHAN Yanlong ${ }^{1, *}$, GAO Bo ${ }^{1}$, WANG Mingxia ${ }^{1}$, HAN Xiyue ${ }^{1}$, ZHANG Hao ${ }^{1}$ \\ 1 Forestry College of Beihua University, Beihua University Science and Technology Innovation Center of Wildland Fire Prevention and Control, Jilin \\ 132013, China \\ 2 Changchun Work Safety Emergency Command and Safety Supervision Information Center, Changchun 130022, China
}

\begin{abstract}
Forest underground fire occurs in the humus. It is a slow, flameless, low-temperature, persistent smoldering combustion maintained by the heat released in the whole combustion process. Therefore, the temperature of underground fire is an important indicator for studying the characteristics of underground fire behavior, and it is also an important basis for monitoring and fighting forest underground fires. Larix gmelinii plantation under five land classifications in Daxing' an Mountains was taken as the study object. Based on the indoor control burning experiment, we studied the temperature changes of smoldering combustion under different land classifications and particle sizes of humus. There was no significant difference between the highest temperatures of smoldering combustion of humus with different particle sizes $(P>0.05)$, while the effects of different land classifications and their interactions on the maximum temperature of smoldering combustion were significant $(P<0.05)$. There were significant differences in the maximum temperature of smoldering combustion between different land classifications under four humus particle sizes $(P<0.05)$. The smoldering combustion temperature of Tatoudianzi could go up to $897.53{ }^{\circ} \mathrm{C}$, which was the highest of all humus particle sizes, and followed by meadow bog,
\end{abstract}

基金项目: 国家重点研发计划课题(2018YFD0600205); 国家自然科学基金项目(31971669); 北华大学研究生创新计划项目(2018-016)

收稿日期:2020-03-26; 网络出版日期:2021-02-24

*通讯作者 Corresponding author.E-mail: shanyl@163.com 
slope mountains, flat mountains, and agricultural land, where the smoldering combustion temperatures of humus were lower. The surface temperature of humus burning in the same land classifications was relatively high, and the highest temperature could reach $618.83{ }^{\circ} \mathrm{C}$. The surface temperature of humus combustion decreased with the increase of combustion time. The relationship between them could be fitted by $y=a \times x^{b}$, and the fitting degree was high $\left(R^{2}>0.9, P<0.01\right)$. The results can provide a scientific and effective theoretical basis for monitoring and fighting forest underground fires in this area.

Key Words : Larix gmelinii plantation; humus; smoldering combustion; temperature changes

森林地下火是发生在腐殖质和泥炭层的一种森林火灾, 它的燃烧是一种阴燃现象。阴燃燃烧与其他形式 的森林燃烧有所不同, 其受外界条件影响较小,一旦发生, 无论是大量降雨、天气变化还是灭火措施, 都很难遏 制, 这就意味着阴燃燃烧可能会持续很长一段时间 (数月或数年) ${ }^{[1]}$ 。中国 1976 年在绥化地区发生的森林地 下火燃烧了长达 6 个月的时间 ${ }^{[2]}$; 1997 年东南亚的极端泥炭火灾事件期间释放了 $0.81-2.57$ 亿 $\mathrm{t}$ 碳, 相当于 当年全球化石燃料碳排放量的 $13 \%-40 \%{ }^{[3]}$; 2009 年发生在西班牙戴米尔国家公园的地下火燃烧了几个星 期 $^{[4]} ; 2010$ 年 7 月, 俄罗斯爆发了大规模的地下火,直接经济损失逾 150 亿美元 ${ }^{[5]}$ 。由此可见,森林地下火对 人类的健康和生态环境造成了重大的影响和危害。由于森林地下火的发生次数仅占森林火灾总次数的 $1 \%$ 左右,而且地下火的火行为与地表火和树冠火有所不同, 其燃烧方式隐蔽无法进行直接地跟踪观测, 很难进行 量化计算与模型的建立 ${ }^{[6]}$ 。所以目前对地下火的研究要显得比较薄弱。国内外学者对地下火的研究多集中 在泥炭地燃烧的碳释放、对地下水位的影响、火环境以及燃烧特征等方面的研究 ${ }^{[7-12]}$ 。

森林地下火是一种缓慢、无焰、低温、持久的阴燃燃烧,整个燃烧过程都是靠自身所释放的热量所维

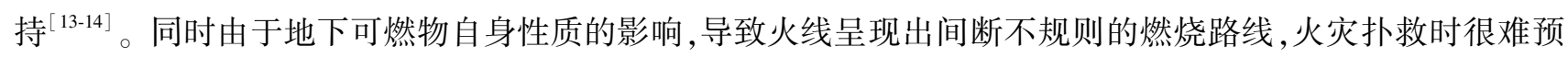
测着火点和火线走势 ${ }^{[15-17]}$ 。所以地下火发生时产生的温度是研究其火行为特征的重要指标, 更是森林地下 火监测和扑救过程中的重要依据。而在现有的研究中以森林腐殖质为研究对象以及对阴燃燃烧温度变化特 征的研究则相对较少。大兴安岭地区是我国地下火频发区域之一, 本研究以大兴安岭兴安落叶松人工林地下 腐殖质为研究对象, 通过室内控制点烧实验, 更加系统地对比分析不同地类和腐殖质粒径对阴燃燃烧最高温 度的影响以及确定地表温度变化与燃烧时间的关系。相关研究成果旨在为该地区森林地下火监测扑救过程 提供科学有效的理论依据,从而最大限度地实现森林地下火的“打早、打小、打了”扑火原则。

\section{1 研究区概况}

大兴安岭位于我国最北端,是我国唯一的寒温带针 叶林区,也是我国面积最大的林区。同时作为国家重要 的生态功能区与生态敏感区, 对我国东北平原乃至华北 平原起着重要的生态屏障作用, 具有特殊的生态地 位 $^{[18-20]}$ 。由于地理位置因素和气象因素影响, 大兴安 岭是我国北方林火多发区, 年均森林过火面积居全国首 位 ${ }^{[21-22]}$ 。而且随着全球气温的不断升高, 导致北方林 区气候偏旱, 林地地温偏高, 森林地下火的发生有增长 的趋势 ${ }^{[10]}$ 。

本研究区域为大兴安岭地区加格达奇森林经营技 术推广站 $\left(123^{\circ} 57^{\prime}-124^{\circ} 0^{\prime} \mathrm{E}, 50^{\circ} 20^{\prime}-50^{\circ} 23^{\prime} \mathrm{N}\right)$ (图 1)。加格达奇位于黑龙江省西北部, 地处大兴安岭

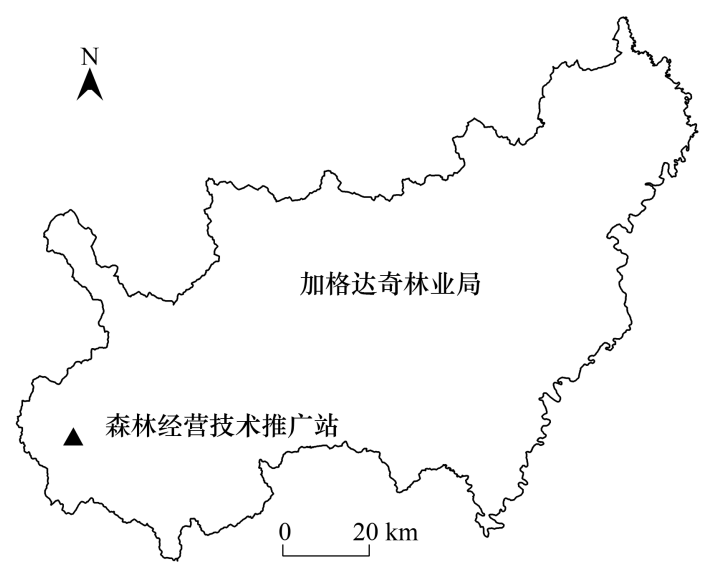

图 1 实验样地

Fig.1 Experimental plots 山脉东南坡属于大陆性季风气候, 四季分明,气候多变, 
一年四季和昼夜温差较大。年平均气温 $-1-2^{\circ} \mathrm{C}$, 年有效积温 $1800-2000^{\circ} \mathrm{C}$, 无霜期 $90-120 \mathrm{~d}$, 年降雨量为 450-500 mm。技术推广站始建于 1973 年, 位于加格达奇区以南 $15 \mathrm{~km}$ 处, 北部和西部与加格达奇林业局的 东风林场相接, 全站施业区经营面积 $7326 \mathrm{hm}^{2}$ 。主要树种为兴安落叶松 (Larix gmelinii)、柞树 ( Quercus mongolica)、白华(Betula platyphylla)、山杨(Populus davidiana)、黑华(Betula davurica) 等 ${ }^{[2,23]}$ 。

\section{2 研究材料与方法}

2.1 野外调查

于 2018 年春季防火期前往大兴安岭地区加格达奇进行野外调查。选择该地区在不同地类下人工种植的 兴安落叶松林为实验样地, 具体包括: 有坡山地、塔头甸子 (塔头甸子与林地的过渡地带)、水湿地、无坡山地、 农用地。在每个地类下随机选取 3 块 $30 \mathrm{~m} \times 20 \mathrm{~m}$ 的实验样地, 挖掘土壤剖面测量腐殖质厚度, 并记录样地的 基本情况,包括:海拔、经纬度、郁闭度等信息 (表 1 )。

表 1 样地基本信息

Table 1 Basic information of sample plot

\begin{tabular}{|c|c|c|c|c|c|c|}
\hline $\begin{array}{l}\text { 地类 } \\
\text { Land classifications }\end{array}$ & $\begin{array}{c}\text { 海拔 } \\
\text { Altitude/m }\end{array}$ & $\begin{array}{c}\text { 经纬度 } \\
\text { Longitude } \\
\text { and latitude }\end{array}$ & $\begin{array}{c}\text { 胸径 } \\
\text { Diameter at } \\
\text { breast height } / \mathrm{cm}\end{array}$ & $\begin{array}{l}\text { 年龄 } \\
\text { Age/a }\end{array}$ & $\begin{array}{l}\text { 郁闭度 } \\
\text { Canopy } \\
\text { closure }\end{array}$ & $\begin{array}{c}\text { 腐殖质厚度 } \\
\text { Humus } \\
\text { thickness/cm }\end{array}$ \\
\hline 有坡山地 Slope mountains & 566.0 & $124.04^{\circ} \mathrm{E}, 50.34^{\circ} \mathrm{N}$ & 22.4 & 22 & 0.7 & 12 \\
\hline 塔头甸子 Tatoudianzi & 406.3 & $124.09^{\circ} \mathrm{E}, 50.32^{\circ} \mathrm{N}$ & 22.5 & 27 & 0.5 & 46 \\
\hline 水湿地 Meadow bog & 379.7 & $124.11^{\circ} \mathrm{E}, 50.30^{\circ} \mathrm{N}$ & 21.2 & 26 & 0.8 & 35 \\
\hline 无坡山地 Flat mountains & 407.2 & $124.08^{\circ} \mathrm{E}, 50.30^{\circ} \mathrm{N}$ & 20.6 & 28 & 0.8 & 40 \\
\hline 农用地 Agricultural land & 553.8 & $124.02^{\circ} \mathrm{E}, 50.35^{\circ} \mathrm{N}$ & 14.8 & 16 & 0.7 & 12 \\
\hline
\end{tabular}

\section{2 可燃物采集与处理}

在每块样地的对角线处分别选取 3 块 $0.5 \mathrm{~m} \times 0.5 \mathrm{~m}$ 的小样方。去掉小样方表层的枯枝落叶, 然后挖掘整 个小样方内的所有腐殖质带回实验室。首先将腐殖质中残留的枯枝落叶和植物根系挑出, 之后将腐殖质装人 档案袋中, 使用鼓风干燥箱 $105^{\circ} \mathrm{C}$, 连续烘干 $48 \mathrm{~h}$ 。最后将烘干的腐殖质进行粉碎并使用标准检验篎在每个 地类下分别篎选粒径 $\leqslant 20$ 目、 $\leqslant 40$ 目、 $\leqslant 60$ 目、 $\leqslant 80$ 目的腐殖质用于控制模拟点烧实验。在控制模拟点烧实 验前为了减小实验误差将篮选好的腐殖质再次放置在鼓风干燥箱中, $105^{\circ} \mathrm{C}$ 连续烘干 $24 \mathrm{~h}$, 使腐殖质趋于 绝干。

\section{3 腐殖质阴燃实验}

本文使用的室内模拟点烧实验装置为自行组装的地下火温度采集系统。采集系统示意图见图 2。模拟 点烧实验使用圆柱形阴燃反应炉, 该装置高 $20 \mathrm{~cm}$, 底厚 $10 \mathrm{~cm}$, 壁厚 $10 \mathrm{~cm}$, 内直径 $10 \mathrm{~cm}$ 。实验所使用阴燃反 应炉的制作材料为硅酸铝陶瓷纤维, 具有很好的保温隔热效果。使用长 $30 \mathrm{~cm}$, 直径 $2 \mathrm{~mm}$ 的 $\mathrm{K}$ 型热电偶采集 腐殖质燃烧过程中的温度变化, 然后通过数据采集模块将采集的数据传输到笔记本电脑。数据采集模块由美 国 NI 公司生产的 16 通道 NI9213 电压采集板卡和 DAQ- 9174 机箱 (4 卡槽) 组成。数据采集软件使用 Labview2018, 该软件可以记录每根热电偶采集到的温度变化曲线。使用远红外加热板作为实验的引燃装置, 并在加热板和电源之间连接控温表使加热板的温度恒定。

将不同地类下不同粒径的腐殖质分别置于阴燃反应炉中, 在阴燃反应炉的侧面自上而下每隔 $3 \mathrm{~cm}$ 共打 6 个小孔。将 $\mathrm{K}$ 型热电偶插人小孔直至腐殖质中间处。使用补偿导线连接热电偶和数据采集模块, 最后将腐 殖质燃烧过程中的温度变化数据传输回笔记本电脑, 数据采集频率为 $10 \mathrm{~s}$ 一次。远红外加热板在使用前先 预热 $1 \mathrm{~h}$ 之后放置在阴燃反应炉上对腐殖质进行加热, 加热时间为 $1.5 \mathrm{~h}$, 加热温度为 $500^{\circ} \mathrm{C}$ 。同时为保证空 气的流通加热板与反应炉之间保留 $2 \mathrm{~cm}$ 的空隙, 并在加热板撤去后, 在腐殖质层表面放置一根热电偶用来监 测地表温度的变化。 


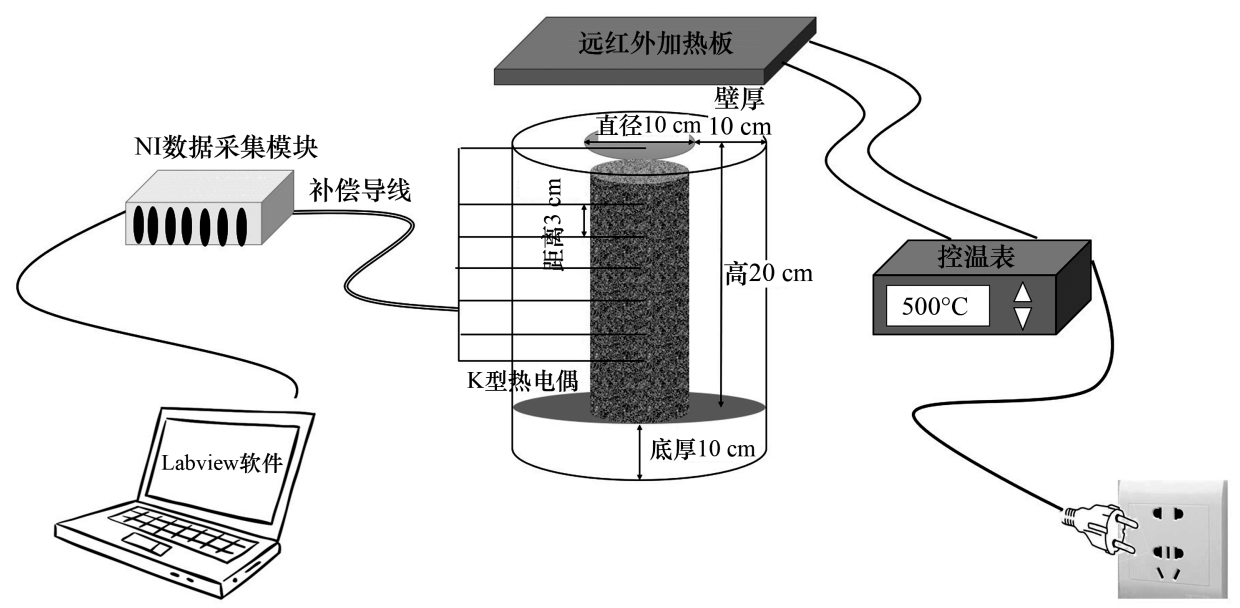

图 2 地下火温度采集系统

Fig.2 Underground fire temperature acquisition system

\section{4 数据处理}

使用 excel 对数据进行初步统计整理。使用 SPSS 进行双因素方差分析,显著水平 0.05 ,多重比较方法为 LSD。使用 origin 软件完成拟合方程并绘制箱式图,其中箱式图的箱体为所有数据的 $20 \%$ - $80 \%$,箱体内的横 线表示均值,上下延长线表示数据的最大值和最小值。

\section{3 结果与分析}

3.1 不同地类和腐殖质粒径对阴燃燃烧最高温度影响的对比分析

在实验过程中我们发现,不同地类的腐殖质阴燃燃烧温度变化都是先升高,达到最高温度之后下降。而 且不同地类和粒径的腐殖质燃烧产生的最高温度有所不同,所以本文对不同地类和腐殖质粒径对阴燃产生的 最高温度的影响进行双因素方差分析。

表 2 可知, 不同地类的腐殖质阴燃燃烧产生的最高温度之间存在极其显著差异 $(P=0.000<0.01)$, 而不同 腐殖质粒径阴燃燃烧的最高点温度之间则不存在差异 $(P=0.238>0.05)$ 。不同地类和腐殖质粒径二者之间的 交互作用也存在显著差异 $(P=0.046<0.05)$,因此应该对两种条件进一步进行简单效应分析。

表 2 不同地类和腐殖质粒径对阴燃燃烧最高点温度影响的方差检验

Table 2 Variance test of the effect of different land classifications and humus particle sizes on the maximum temperature of smoldering combustion

\begin{tabular}{lccc}
\hline 指标 Norm & $d f$ & $F$ & Sig. \\
\hline 地类 Land classifications & 4 & 20.661 & 0.000 \\
腐殖质粒径 Humus particle size & 3 & 1.438 & 0.238 \\
地类×腐殖质粒径 Land classifications×Humus particle size & 12 & 1.908 & 0.046 \\
\hline
\end{tabular}

由表 3 可知, 4 种腐殖质粒径条件下, 不同地类之间阴燃燃烧产生的最高温度皆存在差异。其中当腐殖 质粒径 $\leqslant 20$ 目时,不同地类阴燃燃烧产生的最高温度之间存在显著差异 $(P=0.025<0.05)$ 。其他 3 种腐殖质 粒径下不同地类阴燃燃烧产生的最高温度之间都存在极其显著差异 $(P=0.000<0.01)$ 。

由图 3 可知,腐殖质粒径 $\leqslant 20$ 目时, 塔头甸子腐殖质燃烧的温度最高, 燃烧的最高温度可达 $741.19^{\circ} \mathrm{C}$, 均 值 $631.57^{\circ} \mathrm{C}$; 其次是有坡山地、农用地、水湿地, 燃烧最高温度的均值为 $567.96^{\circ} \mathrm{C} 、 542.79^{\circ} \mathrm{C} 、 528.93^{\circ} \mathrm{C}$, 且 4 种 地类腐殖质燃烧最高温度之间不存在差异; 无坡山地的腐殖质燃烧温度最低, 最低温度仅为 $423.12^{\circ} \mathrm{C}$, 均值为 $458.64^{\circ} \mathrm{C}$, 与塔头甸子和坡地的腐殖质燃烧温度之间存在显著差异。腐殖质粒径 $\leqslant 40$ 目时, 塔头甸子腐殖质 
燃烧的温度同样是最高, 最高温度为 $897.53^{\circ} \mathrm{C}$, 是所有地类的腐殖质燃烧温度最高的,均值为 $686.51^{\circ} \mathrm{C}$, 与其 他 4 种地类之都存在显著差异;其次是水湿地腐殖质燃烧最高温度的均值为 $530.65^{\circ} \mathrm{C}$, 与无坡山地腐殖质燃 烧的温度之间存在显著差异;农用地、有坡山地、无坡山地腐殖质燃烧的温度较低,均值分别为 480.01 、 $461.61 、 369.13^{\circ} \mathrm{C}$, 且这 3 种地类之间不存在显著差异。

\section{表 3 不同腐殖质粒径下不同地类阴燃燃烧最高点温度的简单效应分析}

Table 3 Simple effect analysis of maximum temperature of smoldering combustion at different land classifications under different humus particle sizes

\begin{tabular}{lcc}
\hline 参数 Parameter & $F$ & Sig. \\
\hline 地类×腐殖质粒径 $(\leqslant 20$ 目) Land classifications * Humus particle size $(\leqslant 20$ mesh $)$ & 2.95 & 0.025 \\
地类×腐殖质粒径 $(\leqslant 40$ 目) Land classifications * Humus particle size $(\leqslant 40$ mesh $)$ & 10.23 & 0.000 \\
地类×腐殖质粒径 $(\leqslant 60$ 目) Land classifications * Humus particle size $(\leqslant 60$ mesh $)$ & 6.28 & 0.000 \\
地类×腐殖质粒径 $(\leqslant 80$ 目) Land classifications * Humus particle size $(\leqslant 80$ mesh $)$ & 5.99 & 0.000 \\
\hline
\end{tabular}

腐殖质粒径 $\leqslant 60$ 目时塔头甸子的腐殖质燃烧温度最高为 $650.71^{\circ} \mathrm{C}$, 与其他 4 种地类之间也存在显著差 异; 其次是水湿地腐殖质燃烧时的最高温度均值为 $546.48^{\circ} \mathrm{C}$, 与有坡山地和无坡山地之间存在显著差异; 农用 地、无坡山地、有坡山地的腐殖质燃烧温度较低，且 3 者之间不存在显著差异。腐殖质粒径 $\leqslant 80$ 目时塔头甸子 的腐殖质燃烧最高温度均值为 $650.19^{\circ} \mathrm{C}$,与农用地和有坡山地之间存在显著差异; 其次是水湿地和无坡山地, 腐 殖质燃烧的最高温度均值分别为 $587.41 、 539.24^{\circ} \mathrm{C}$, 二者之间不存在显著差异,但是皆与有坡山地之间存在显著 差异;农用地和有坡山地腐殖质燃烧温度较低,分别为 $481.19 、 420.94^{\circ} \mathrm{C}$, 且二者之间不存在显著差异。

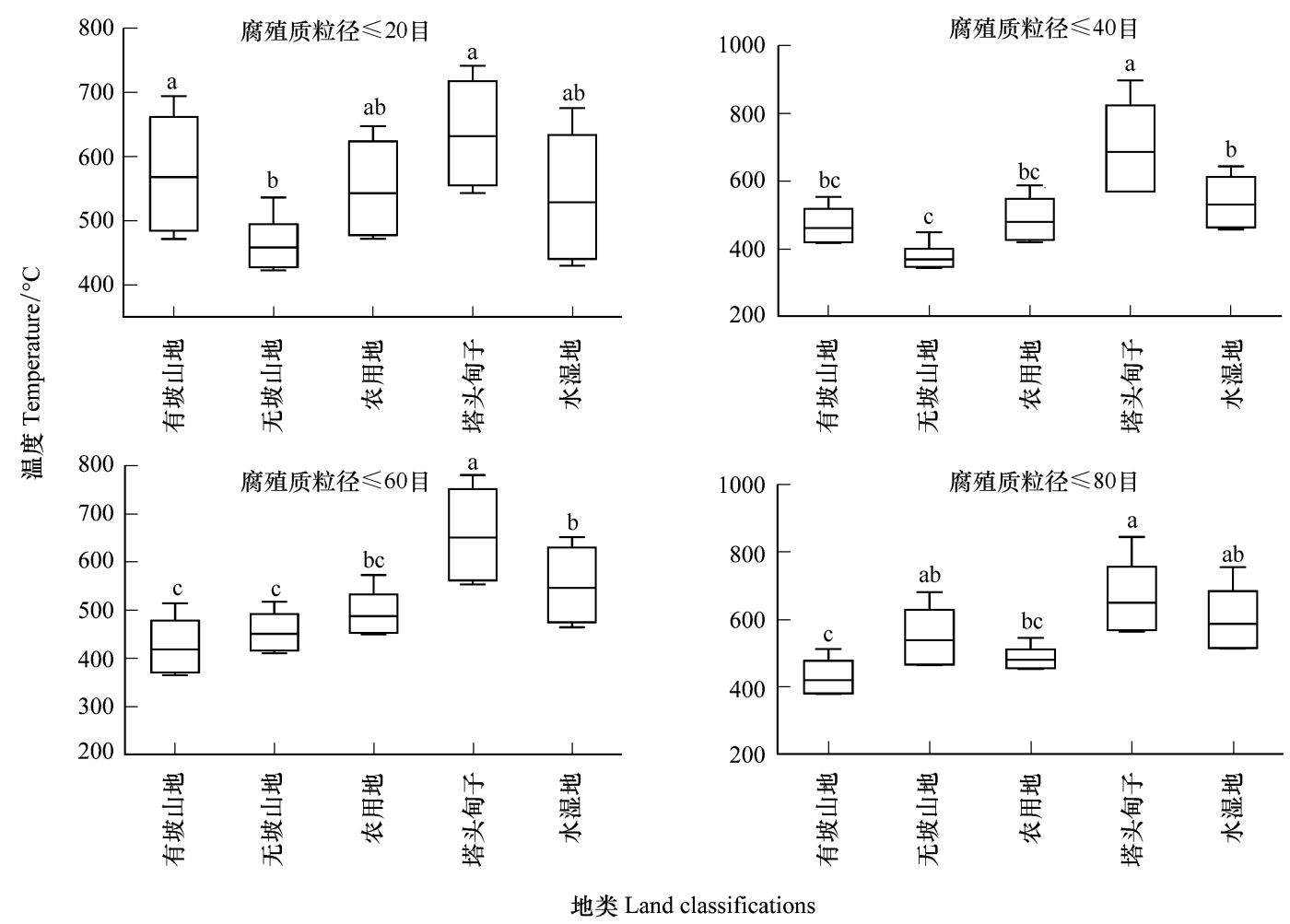

图 3 不同腐殖质粒径下不同地类阴燃燃烧最高温度的多重比较

Fig.3 Multiple comparisons of the maximum temperature of smoldering combustion in different land classifications under different humus particle sizes

图上存在任意一个相同的字母表示差异不显著 $(P<0.05)$ 


\section{2 腐殖质阴燃燃烧地表温度变化特征}

\subsection{1 不同地类下地下火燃烧地表最高温度}

由表 4 可知,塔头甸子的腐殖质燃烧地表最高温度除粒径 $\leqslant 60$ 目以外都是最高的; 其中腐殖质 $\leqslant 40$ 地表 温度最高, 为 $618.83^{\circ} \mathrm{C}$; 其次是粒径 $\leqslant 80$ 目地表温度为 $615.78^{\circ} \mathrm{C}$, 粒径 $\leqslant 20$ 目的地表温度为 $545.56^{\circ} \mathrm{C}$; 粒 径 $\leqslant 60$ 目时地表温度最低, 为 $450.13^{\circ} \mathrm{C}$ 。有坡山地条件下也是腐殖质粒径 $\leqslant 40$ 目时地表温度最高, 为 $529.87^{\circ} \mathrm{C}$; 其次是腐殖质粒径 $\leqslant 20$ 目时地表最高温度为 $471.86^{\circ} \mathrm{C}$; 腐殖质粒径 $\leqslant 60$ 目时地表温度最低, 为 $416.37^{\circ} \mathrm{C}$ 。无坡山地和农用地条件下腐殖质燃烧地表的最高温度都随着粒径的增加而升高, 腐殖质粒径 $\leqslant 80$ 目时温度最高分别为 $544.61^{\circ} \mathrm{C} 、 585.76^{\circ} \mathrm{C}$; 粒径 $\leqslant 20$ 目温度最低, 分别为 $485.13^{\circ} \mathrm{C} 、 511.82^{\circ} \mathrm{C}$ 。水湿地条件下 则是腐殖质粒径 $\leqslant 80$ 目时地表温度最高, 为 $573.50^{\circ} \mathrm{C}$; 粒径 $\leqslant 40$ 目时地表温度, 最低为 $511.55^{\circ} \mathrm{C}$ 。

表 4 不同地类下不同粒径腐殖质阴燃燃烧地表最高温度

Table 4 Maximum surface temperature of smoldering combustion of humus with different particle sizes under different land classifications

\begin{tabular}{|c|c|c|c|c|c|}
\hline \multirow{2}{*}{$\begin{array}{c}\text { 腐殖质粒径/目 } \\
\text { Humus particle } \\
\text { size/mesh }\end{array}$} & \multicolumn{5}{|c|}{$\begin{array}{c}\text { 地表最高温度 } \\
\text { Maximum surface temperature } /{ }^{\circ} \mathrm{C}\end{array}$} \\
\hline & $\begin{array}{c}\text { 有坡山地 } \\
\text { Slope mountains }\end{array}$ & $\begin{array}{c}\text { 无坡山地 } \\
\text { Flat mountains }\end{array}$ & $\begin{array}{c}\text { 农用地 } \\
\text { Agricultural land }\end{array}$ & $\begin{array}{l}\text { 塔头甸子 } \\
\text { Tatoudianzi }\end{array}$ & $\begin{array}{c}\text { 水湿地 } \\
\text { Meadow bog }\end{array}$ \\
\hline$\leqslant 20$ & 471.86 & 485.13 & 511.82 & 545.56 & 541.76 \\
\hline$\leqslant 40$ & 529.87 & 485.45 & 513.34 & 618.83 & 511.55 \\
\hline$\leqslant 60$ & 416.37 & 522.95 & 561.23 & 450.13 & 555.31 \\
\hline$\leqslant 80$ & 440.82 & 544.61 & 585.76 & 615.78 & 573.50 \\
\hline
\end{tabular}

3.2.2 不同地类下地下火燃烧地表温度与时间的关系

基于 $y=a \times x^{b}$ 方程分析 5 种地类的不同粒径腐殖质燃烧地表温度与时间的关系。从表 5 可以看出各个 条件下拟合的方程 $R^{2}$ 介于 $0.97-0.99$ 之间, 显著性都小于 0.01 , 说明地表温度与时间之间的关系符合 $y=a \times x^{b}$ 方程的变化趋势, 且拟合效果极好。且 $\mathrm{b}$ 值都要小于 0 , 说明腐殖质燃烧的地表温度随燃烧时间的 增加而逐渐降低。

\section{4 讨论}

\section{1 腐殖质阴燃燃烧温度研究的重要性}

林火行为是指森林可燃物从被点燃开始到发生发展直至熄灭的整个过程中所表现出的各种现象和特 征 ${ }^{[24]}$ 。森林地表火和树冠火发生时整个燃烧过程人们可以通过肉眼或借助无人机、卫星遥感等手段进行观 测, 这两种林火类型也一直是国内外学者研究的重点, 经过多年的研究针对于这两种林火的预防、监测和扑救 方法和技术要比地下火成熟 ${ }^{[17]}$ 。对于地下火来说, 由于其隐蔽性极强且发生时多伴随着地表火发生,所以在 扑救过程中极易被忽略, 而当地下火蔓延到地缝或者腐殖质较薄的地区就会转变为地表火或是树冠火。在这 种情况下引起的林火随机性很强, 时间和地点等都很难预测, 稍有不慎就有可能发展成重特大森林火灾。森 林地下火与地表火和树冠火不同,地下火发生时没有火焰 ${ }^{[25]}$, 所以很难对其火强度、蔓延速度等火行为指标 进行研究。但是任何物质的燃烧都会释放热量,森林地下火也是如此,所以地下火燃烧所产生的温度是开展 地下火相关研究的基础。本文通过室内控制点烧实验, 对大兴安岭地区不同地类下种植的人工兴安落叶松林 腐殖质阴燃燃烧产生的温度变化特征进行了分析。研究过程中腐殖质阴燃燃烧的特点和温度变化趋势与 Huang 和辛颖等人研究结果基本相符 ${ }^{[26-27]}$, 而且本研究所选取的实验样地和可燃物具有代表性, 研究结果具 有较高的实用性。

\section{2 腐殖质阴燃燃烧温度特征}

可燃物是森林燃烧的物质基础, 是燃烧三要素之一, 可燃物的空间分布、大小、形状等特征影响着林火的 发生及发展。通过简单效应分析发现,不同腐殖质粒径下不同地类的腐殖质阴燃燃烧温度之间存在显著差 
异。何诚 ${ }^{[28]}$ 、李世友 ${ }^{[29]}$ 等学者在相关研究中也指出不同类型的可燃物所表现的阴燃燃烧特征也是不同的， 这与本研究的结果基本一致。在 5 种地类中塔头甸子在任何一种腐殖质粒径下阴燃燃烧温度都是最高的,最 高温度可达 $897.53^{\circ} \mathrm{C}$ 。辛颖 ${ }^{[26]}$ 、Valeria ${ }^{[1]} 、$ Restuccia ${ }^{[30]}$ 等学者进行的相关研究中, 阴燃燃烧的最高温度为 $600^{\circ} \mathrm{C}$ 左右, 而本研究进行腐殖质阴燃燃烧实验时产生的最高温度要远高于 $600^{\circ} \mathrm{C}$, 表明腐殖质燃烧时所释放 的热量还有很大的上升空间。这样高的燃烧温度对植物的根系损伤很大, 可直接导致植物死亡, 从而造成树 木的大面积倒伏, 同时对土壤结构和地下水位也有一定的影响。这是由于塔头甸子是由沼泽地上生长着以苔 草为主的草本沼泽植物而形成的。由于沼泽地的通透性差, 导致有机质不易分解, 地下存在大量的草根 ${ }^{[31]}$ 。 胡海清 ${ }^{[32]}$ 和洪娇娇 ${ }^{[33]}$ 等人在相关研究中提出可燃物的有机质含量对林火强度存在一定的影响。而大兴安 岭地区还分布着大面积在塔头甸子种植的兴安落叶松林 ${ }^{[16]}$, 所以该地类是森林地下火的易发区和重灾区。

表 5 不同地类下不同粒径腐殖质阴燃燃烧地表温度与时间的关系

Table 5 Relationship between surface temperature and time of smoldering combustion of humus with different particle sizes under different land classifications

\begin{tabular}{|c|c|c|c|c|}
\hline $\begin{array}{l}\text { 地类 } \\
\text { Land classifications }\end{array}$ & $\begin{array}{c}\text { 腐殖质粒径/目 } \\
\text { Humus particle size/mesh }\end{array}$ & $R^{2}$ & Sig. & $\begin{array}{l}\text { 方程 } \\
\text { Equation }\end{array}$ \\
\hline 有坡山地 & $\leqslant 20$ & 0.99 & 0.00 & $y=986.97 \times x^{-1.33}$ \\
\hline \multirow[t]{3}{*}{ Slope mountains } & $\leqslant 40$ & 0.99 & 0.00 & $y=961.09 \times x^{-1.15}$ \\
\hline & $\leqslant 60$ & 0.99 & 0.00 & $y=922.54 \times x^{-1.14}$ \\
\hline & $\leqslant 80$ & 0.99 & 0.00 & $y=1017.50 \times x^{-1.20}$ \\
\hline 无坡山地 & $\leqslant 20$ & 0.99 & 0.00 & $y=720.42 \times x^{-1.08}$ \\
\hline \multirow[t]{3}{*}{ Flat mountains } & $\leqslant 40$ & 0.99 & 0.00 & $y=857.11 \times x^{-1.14}$ \\
\hline & $\leqslant 60$ & 0.99 & 0.00 & $y=795.93 \times x^{-1.03}$ \\
\hline & $\leqslant 80$ & 0.99 & 0.00 & $y=973.54 \times x^{-1.12}$ \\
\hline 农用地 & $\leqslant 20$ & 0.99 & 0.00 & $y=938.71 \times x^{-1.32}$ \\
\hline \multirow[t]{3}{*}{ Agricultural land } & $\leqslant 40$ & 0.99 & 0.00 & $y=734.99 \times x^{-1.10}$ \\
\hline & $\leqslant 60$ & 0.99 & 0.00 & $y=894.72 \times x^{-1.13}$ \\
\hline & $\leqslant 80$ & 0.98 & 0.00 & $y=800.53 \times x^{-1.24}$ \\
\hline 塔头甸子 & $\leqslant 20$ & 0.99 & 0.00 & $y=1097.19 \times x^{-1.32}$ \\
\hline \multirow[t]{3}{*}{ Tatoudianzi } & $\leqslant 40$ & 0.99 & 0.00 & $y=1277.15 \times x^{-1.47}$ \\
\hline & $\leqslant 60$ & 0.97 & 0.00 & $y=788.16 \times x^{-1.29}$ \\
\hline & $\leqslant 80$ & 0.99 & 0.00 & $y=1380.88 \times x^{-1.48}$ \\
\hline 水湿地 & $\leqslant 20$ & 0.99 & 0.00 & $y=727.23 \times x^{-1.03}$ \\
\hline \multirow[t]{3}{*}{ Meadow bog } & $\leqslant 40$ & 0.99 & 0.00 & $y=1072.25 \times x^{-1.08}$ \\
\hline & $\leqslant 60$ & 0.99 & 0.00 & $y=805.77 \times x^{-1.13}$ \\
\hline & $\leqslant 80$ & 0.99 & 0.00 & $y=1104.17 \times x^{-1.30}$ \\
\hline
\end{tabular}

4.3 腐殖质阴燃燃烧地表温度在地下火监测和扑救中应用建议

由于地下火具有极强的隐蔽性,所以在扑救过程中存在着极大的困难和危险,目前挖掘防火沟是扑灭地 下火最有效的方法,但是地下火火场边界很难界定,因此在扑救过程中会耗费大量的人力物力财力。并且具 有经验的扑救人员讲,下雨天或下雪天最有利于地下火的监测和扑救, 因为地下火的燃烧会引起地表雨水蒸 发或积雪融化,极易被森林消防人员发现。所以地表温度可以作为监测地下火发生和确定火场边界的重要依 据。根据对腐殖质阴燃燃烧地表温度变化监测可知, 不同地类腐殖质燃烧的地表温度较高, 最高温度可达 $618.83^{\circ} \mathrm{C}$ 。如此高的地表温度极有可能会给扑救人员带来损伤,所以在扑救过程中非必要情况不要进人火 场,可以先大量浇水来降低地表温度,进人火场后也要注意脚部和腿部的防护。腐殖质燃烧地表温度随时间 的增加而降低。这是由于森林地下火刚发生时,着火点距离地表较近,导致地表温度较高。但是随着燃烧向 下蔓延,深层腐殖质燃烧所释放的热量被上层的可燃物阻隔,地表的温度也在逐渐降低直至稳定。针对易发 
生地下火的地区,如塔头甸子和水湿地等地发生地表火时要提前挖掘防火沟,扑救时对腐殖质也应该进行浇 水降温处置。一旦忽略地下火的发生,之后将很难监测, 从而造成更大的森林资源损失。

\section{5 结论}

腐殖质粒径对阴燃燃烧最高温度的影响不存在显著差异,在相同腐殖质粒径条件下不同地类对阴燃燃烧 最高温度存在影响。塔头甸子和水湿地的腐殖质阴燃燃烧温度较高, 有坡山地、农用地、无坡山地的腐殖质阴 燃燃烧温度相对较低。所有地类的腐殖质阴燃燃烧地表温度随时间的增加而降低,变化趋势符合 $y=a \times x^{b}$ 方程。当燃烧时间为 $15-20 \mathrm{~h}$ 时地表温度基本趋于平稳,并且当地表温度稳定时也要高于室温 $1-5^{\circ} \mathrm{C}$ 。

\section{参考文献 (References) :}

[ 1 ] Zaccone C, Rein G, D' orazio V, Hadden R M, Belcher C M, Miano T M. Smouldering fire signatures in peat and their implications for palaeoenvironmental reconstructions. Geochimica et Cosmochimica Acta, 2014, 137: 134- 146.

[ 2 ] 何诚, 舒立福, 张思玉. 我国寒温带林区地下火发生特征及研究. 森林防火, 2014, (4) : 22-25.

[ 3 ] Page S E, Siegert F, Rieley J O, Boehm H D V, Jaya A, Limin S. The amount of carbon released from peat and forest fires in Indonesia during 1997. Nature, 2002, 420(6911): 61-65.

[ 4 ] Rein G. Smouldering fires and natural fuels//Belcher C M, ed. Fire Phenomena and the Earth System: An Interdisciplinary Guide to Fire Science. Chichester: John Wiley \& Sons, Ltd., 2013.

[ 5 ] 赵凤君, 舒立福, 姚树人. 俄罗斯 2010 年森林大火及教训. 森林防火, 2011, (4) : 43-46.

[6] 王秋华. 森林火灾燃烧过程中的火行为研究 [D]. 北京: 中国林业科学研究院, 2010.

[ 7 ] Davies G M, Gray A, Rein G, Legg C J. Peat consumption and carbon loss due to smouldering wildfire in a temperate peatland. Forest Ecology and Management, 2013, 308: 169-177.

[ 8 ] Carlson K M, Goodman L K, May-Tobin C C. Modeling relationships between water table depth and peat soil carbon loss in Southeast Asian plantations. Environmental Research Letters, 2015, 10(7): 074006.

[ 9 ] Johnston D C, Turetsky M R, Benscoter B W, Wotton B M. Fuel load, structure, and potential fire behaviour in black spruce bogs. Canadian Journal of Forest Research, 2015, 45(7): 888-899.

[10] 舒立福, 王明玉, 田晓瑞, 李忠琦, 肖永军. 大兴安岭林区地下火形成火环境研究. 自然灾害学报, 2003, 12(4): 62-67.

[11] 何诚, 舒立福, 张思玉, 王越, 王明玉. 大兴安岭森林草原地下火阴燃特征研究. 西南林业大学学报, 2020, 40(2): 103-110.

[12] 尹赛男, 单延龙, 宋光辉, 韩喜越, 高博. 不同粒径腐殖质火垂直燃烧特征研究. 中南林业科技大学学报, 2019, 39(10): 95-101.

[13] Ohlemiller T J. Modeling of smoldering combustion propagation. Progress in Energy and Combustion Science, 1985, 11(4): 277-310.

[14] Rein G, Cleaver N, Ashton C, Pironi P, Torero J. The severity of smouldering peat fires and damage to the forest soil. Catena, 2008, 74( 3) : 304309.

[15] 于立峰. 森林地下火蔓延方式及火行为特点研究. 林业勘查设计, 2012, (2): 111-112.

[16] 张吉利, 邸雪颖. 地下火及阴燃研究进展. 温带林业研究, 2018, 1(3): 19-22, 62-62.

[17] 宗学政, 田晓瑞. 林火行为和扑救技术研究进展. 世界林业研究, 2019, 32(6): 31-36.

[18］梁东哲, 赵雨森, 曹杰, 辛颖. 不同恢复方式下大兴安岭重度火烧迹地林地土壤温室气体通量. 生态学报, 2019, 39(21): 7950-7959.

[19] 陈韵如, 杨扬, 张喜亭, 杨艳波, 王慧梅, 王文杰. 大兴安岭森林火烧恢复年限对土壤磷及其有效性的影响. 生态学报, 2019, 39(21): 7977-7986.

[20] 胡海清, 罗碧珍, 魏书精, 魏书威, 文正敏, 孙龙, 罗斯生, 王立明, 马洪斌. 大兴安岭 5 种典型林型森林生物碳储量. 生态学报, 2015, $35(17): 5745-5760$.

[21] 胡海清, 魏书精, 孙龙. 1965-2010 年大兴安岭森林火灾碳排放的估算研究. 植物生态学报, 2012, 36(7): 629-644.

[22] 杨达, 吴志伟, 梁宇, 贺红士. 火干扰对森林碳库影响的量化研究进展. 世界林业研究, 2015, 28(1) : 37-42.

[23] 张吉利. 加格达奇和抚远可燃物湿度码及含水率动态研究 [D]. 哈尔滨: 东北林业大学, 2018.

[24] 胡海清. 林火生态与管理. 北京: 中国林业出版社, 2005.

[25] 唐抒圆, 李华, 单延龙, 肖云, 尹赛男. 森林地下火特征及防控措施. 世界林业研究, 2019, 32(3): 42-48.

[26] 辛颖, 历美岑. 粒径对森林腐殖质阴燃传播的影响. 消防科学与技术, 2017, 36( 8) : 1037-1040.

[27] Huang X Y, Rein G. Downward spread of smouldering peat fire: the role of moisture, density and oxygen supply. International Journal of Wildland Fire, 2017, 26(11): 907-918.

[28] 何诚, 舒立福, 刘超, 王越, 张元吴, 张运生. 南方人工林地阴燃火温度变化特征研究. 林业工程学报, 2020, 5(2): 151-157.

[29] 李世友, 马爱丽, 王学飞, 马瑞杰, 张桥蓉, 袁俊杰. 3 种森林调落物的阴燃特性. 中南林业科技大学学报, 2009, 29(1): 60-63, 78-78.

[30] Restuccia F, Huang X Y, Rein G. Self-ignition of natural fuels : can wildfires of carbon-rich soil start by self-heating? Fire Safety Journal, 2017, 91: 828-834.

[31] 李继承, 赵玉英, 高瑶琴, 刘广林. 沼泽地造林后生态因子的变化与效益初步分析. 林业科学, 1985, 21(1): 80-85.

[32] 胡海清, 罗斯生, 罗碧珍, 魏书精, 王振师, 吴泽鹏. 林火干扰对广东省杉木林土壤有机碳及其组分的影响. 北京林业大学学报, 2019, 41(12) : 108-118.

[33] 洪娇娇, 陈宏伟, 齐淑艳, 刘娜, 许晶. 火干扰强度对大兴安岭森林地上植被碳储量的影响. 应用生态学报, 2017, 28(8): 2481-2487. 